\title{
LOS CHACLLA EN EL VALLE DE ARAHUAY. UN MECANISMO DE CONTROL INCA DE LA CUENCA ALTA DEL RIO CHILLÓN ${ }^{1}$
}

\author{
GUIDO CASAVERDE Ríos \\ MINISTERIO DE CULTURA \\ guidocasaverde@hotmail.com
}

\section{RESUMEN}

La arquitectura prehispánica del periodo Inca presente en los valles de Arahuay y el Sta. Eulalia, manifiestan semejanzas que muy probablemente estén asociados al control indirecto Inca por medio de los Chaclla provenientes del valle de Sta. Eulalia del Rímac, que según la documentación etnohistórica eran aliados de los Inca para la administración de una parte de la cuenca del Chillón.

Palabras Clave: Chaclla, Inca, Horizonte Tardío, Tahuantinsuyo, Chuya, Huambo, Valle de Arahuay, Valle de Chillon, Tunshuhuilca.

\section{ABSTRACT}

The pre-hispanic period Inca architecture present in the valleys of Arahuay and Sta. Eulalia, show similarities that are most likely associated with the Inca indirect control through the valley Chaclla from Sta. Eulalia del Rímac, which the documents were ethnohistoric Inca allies for managing a portion of the basin of Chillon.

KeYworDs: Chaclla, Inca, Late Horizon, Tahuantinsuyo, Chuya, Huambo, Valley Arahuay, Valley Chillon, Tunshuhuilca.

1.- El presente trabajo fue elaborado como parte de las investigaciones realizadas sobre las "Redes Viales Inca en la Cuenca Alta del Río Chillón", desarrollado en los años 1994 y 1995. 


\section{INTRODUCCIÓN}

Varios autores que han investigado la época Inca en el Chillón, han sostenido la hipótesis de un evidente control Inca de esta región. Los indicios que permiten postular tal argumento van desde la relativa presencia de estructuras arquitectónicas de factura Inca en los sitios locales, hasta la potencial aceptación etnohistórica de una alianza entre el estado Inca y el grupo étnico Chaclla procedente de la cuenca alta del Rímac. Poco se ha hecho por esclarecer el desarrollo del control Inca en la región, la falta de investigaciones sobre las peculiares manifestaciones culturales de las sociedades de los períodos preincaicos de la cuenca y sus vecinas, han complicado aún más este panorama.

Ante estas limitaciones, $y$ en un esfuerzo por entender parte de la problemática Inca, focalizamos nuestras investigaciones en el valle del Arahuay, uno de los tributarios más importantes y estratégicos del río Chillón. De esta manera, y considerando la cercanía del valle de Arahuay con los territorios del antiguo señorío de Chaclla, manejamos la hipótesis de que parte del control Inca de esta región estuvo a cargo de sus aliados provenientes de la sierra del Rímac. Como producto de las investigaciones arqueológicas, se encontraron semejanzas entre los sitios arqueológicos de las dos regiones contiguas, dándonos algunos indicios sobre el posible control administrativo de parte de los de Chaclla en el Chillón, a través del valle de Arahuay.

Los resultados de las investigaciones que presentamos a continuación son de carácter preliminar, esperamos que futuros trabajos aclaren la problemática

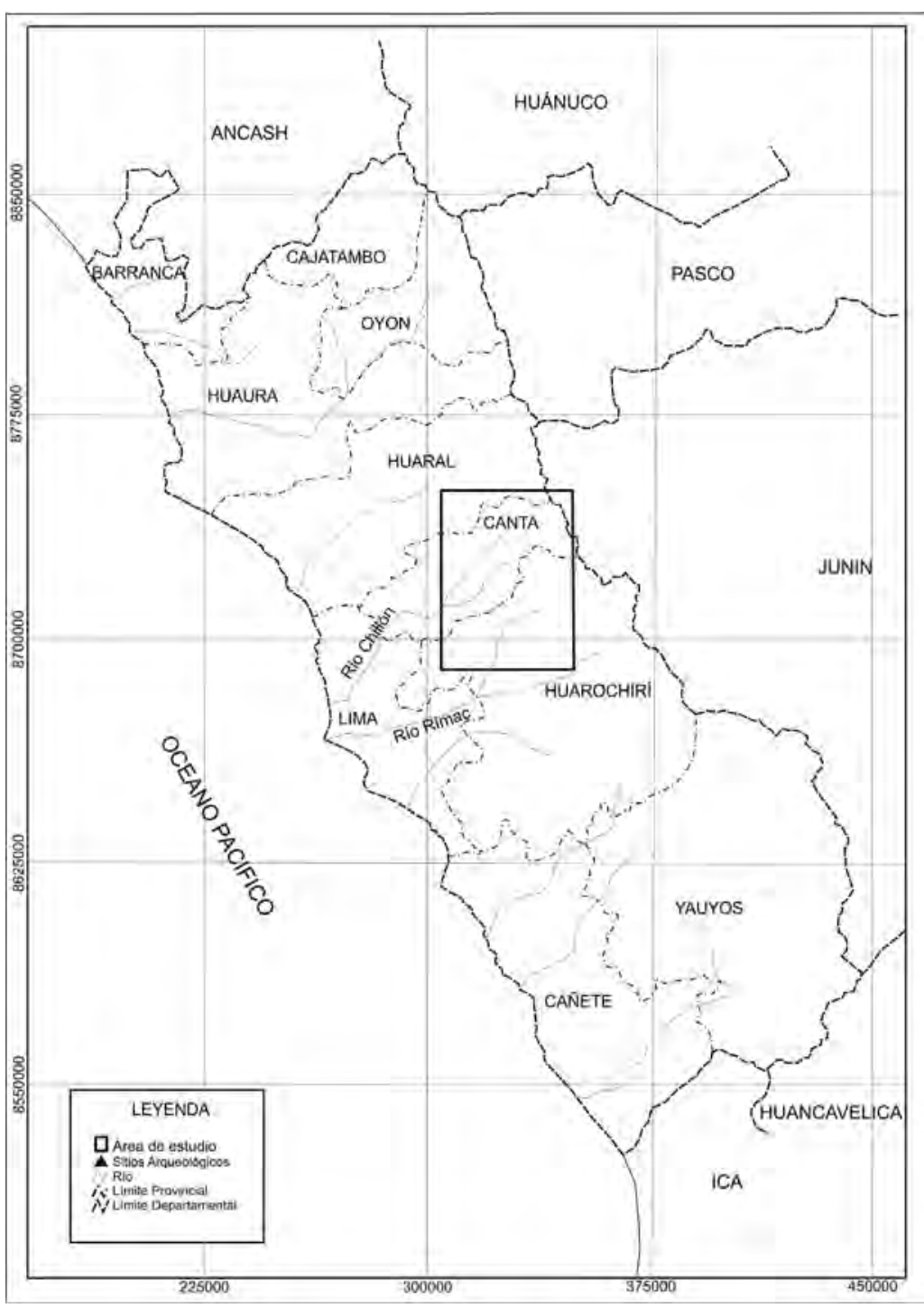

Figura 1: Mapa de ubicación del área de estudio. Inca de la región. 


\section{El Valle de Arahuay}

La cuenca del río Chillón (Figura 1 y 2) se ubica en el Departamento de Lima, recorre de este a oeste las actuales provincias de Canta en la sierra y de Lima en la costa. Esta cuenca se halla conformada por dos importantes tributarios, el valle del Chillón en el norte y el de Arahuay al sur, ambos se unen en las cercanías del poblado de Sta. Rosa de Quives para formar el río Chillón. Hacia el sur del valle de Arahuay, se encuentra el valle del río Sta. Eulalia importante afluente del río Rímac. Durante los tiempos prehispánicos el valle de Arahuay tuvo una importancia socioeconómica y política, siendo clave para el dominio y control de los recursos producidos en esta parte.

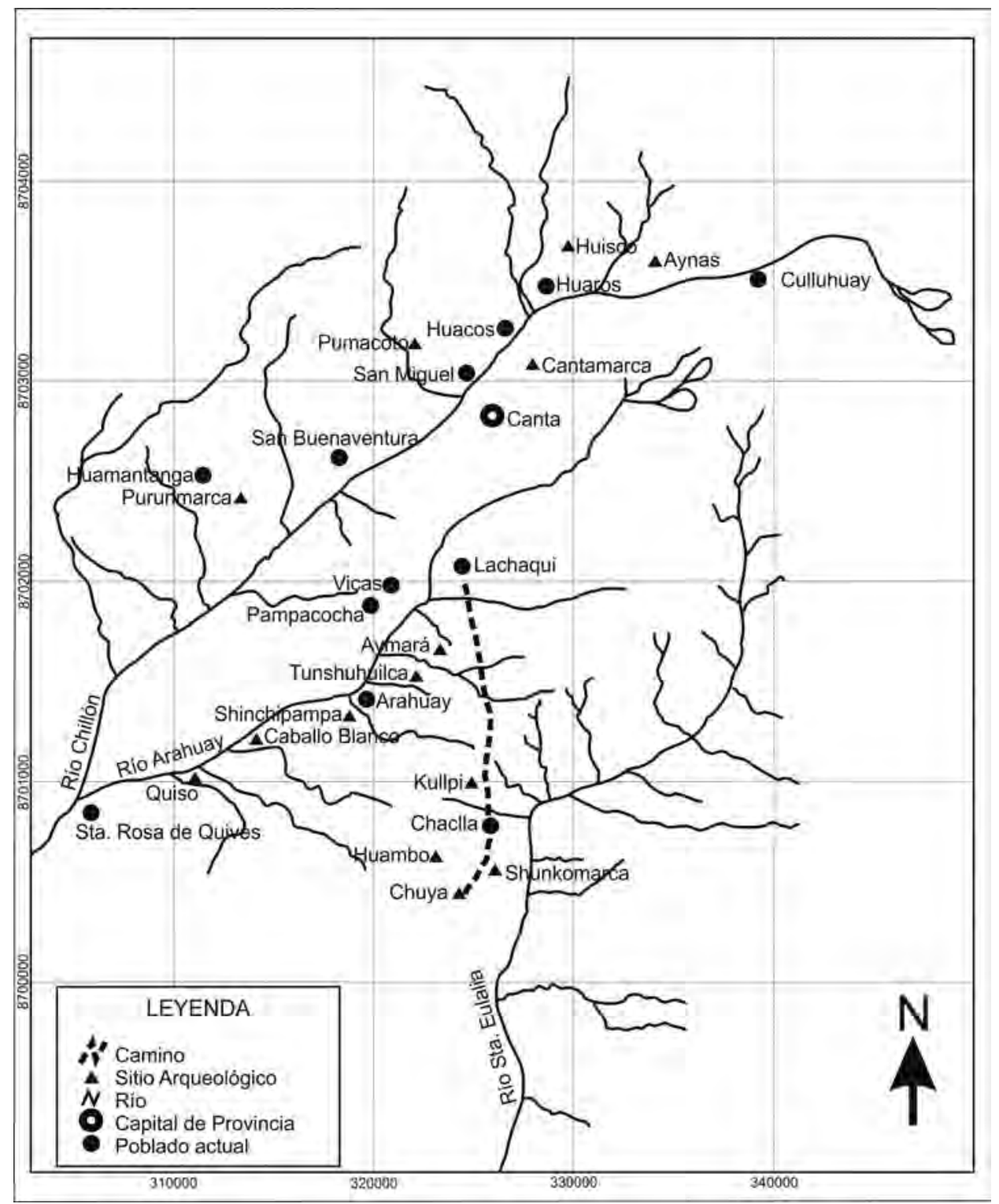

Figura 2: Ubicación de sitios arqueológicos, caminos y localidades importantes del área de estudio. 


\section{ANTECEDENTES}

El Período Intermedio Tardío en el Chillón, está caracterizado según las fuentes documentales por una constancia de conflictos interétnicos, por el aprovechamiento de los recursos básicos de subsistencia y de aquellos productos importantes para los fines ceremoniales; así, como para la redistribución económica que practicaban los líderes sociales como mecanismos de control social y político. Según la arqueología está constancia de guerras o conflictos ha quedado expresada en las características físicas y de ubicación de los asentamientos preincaicos, los cuales estratégicamente se encontraban en zonas elevadas y de difícil acceso, dotados además de murallas defensivas. Estas cualidades son recurrentes en la mayor parte de los sitios arqueológicos tardíos de la sierra de Lima, pero se diferencian en las particularidades de estilo o de técnica que cada formación social daba a sus manifestaciones culturales.

La arquitectura de los asentamientos prehispánicos de la parte alta del río Chillón, es en su mayoría de planta circular, aunque también existen construcciones de planta cuadrangular semejante a los estilos arquitectónicos de la cuenca vecina del río Chancay ubicado al norte del río Chillón (Farfán 1995:60). Mientras tanto, los asentamientos de la margen izquierda del valle de Arahuay poseen estructuras de planta rectangular con divisiones al interior, como lo ponen en evidencia los sitios arqueológicos de Tunshuhuilca, Sinchipampa y Caballo Blanco, esta arquitectura se asemeja a los sitios de la margen derecha del río Sta. Eulalia, cuyas construcciones son también rectangulares con varias divisiones internas, las estructuras rodean patios y su planeamiento es aglutinado, ejemplo de estos sitios representativos son Sunkomarca (Figura 3) y Kullpi.

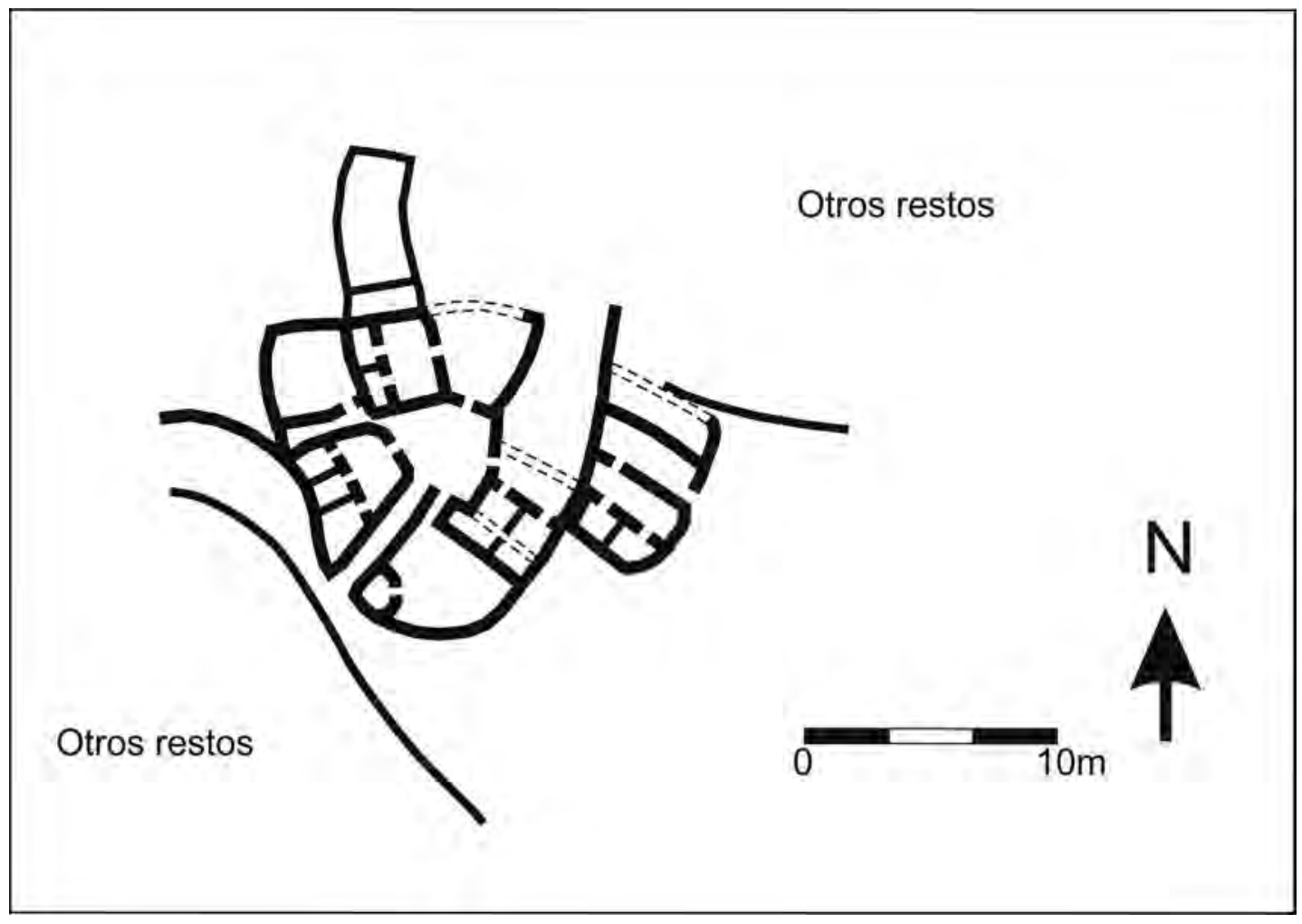

Figura 3: Unidad arquitectónica del sitio arqueológico Sunkomarca. (Redibujado en base a Pareja 1995). 
Tal semejanza arquitectónica entre los sitios de uno y otro valle es comprensible desde el punto de vista de los procesos históricos ocurridos en las relaciones económicas y políticas sostenidas entre las etnias que usufructuaban las tierras en beneficio de determinados productos, así, como en los mecanismos empleados para tener acceso a ellas como las llamadas alianzas en tiempos de paz. La prolija información recuperada de los documentos etnohistóricos revela un buen número de estos acontecimientos llevados a cabo antes de la llegada de los cuzqueños, en los cuales se denota la participación de varios grupos étnicos, entre ellos, los de Chaclla en los terrenos de Quives, cuyo acceso podía ser posible gracias a las quebradas de comunicación que los vinculaban con los contiguos valles del Arahuay y del Sta. Eulalia.

Para la época Inca se producen cambios en las estructuras sociopolíticas de los grupos étnicos. Según las fuentes documentales, los ejércitos Incas hacen su aparición por primera vez en el chillón, durante el siglo XV guiados por el soberano cuzqueño Túpac Yupanqui, pero ¿Qué razones y causas originaron tal conquista?. Sabemos que los Incas se anexaban tierras y mano de obra para reproducir su organización económica y continuar expandiéndose. Por otro lado la etnohistoria es muy enfática con respecto a los atributos mágico-religioso de la coca y de los cocales de la Chaupiyunga de los valles costeños del Chillón, Rímac y Lurín (Rostworowski 1973, 1977: 177-178, Espinosa Soriano 1992: 117), esta habrá sido una de las razones por la cual, el estado cuzqueño anexo esta importante región.

La ocupación Inca del Chillón, ha sido fundamentada por investigaciones etnohistóricas (Rostworowski 1978) y arqueológicas (Villar Córdova 1935, Casana 1976, Dillehay 1977, Silva 1992, Marcus y Silva 1988, Farfán 1992, 1995). Todos estos estudios nos indican, que los Incas tuvieron un control de la sierra del Chillón².

El control Inca fue diferente en cada región, este fue organizado con flexibilidad y cada una de ellas podía reflejar una relación especial existente entre las variadas necesidades del estado y las diferentes circunstancias ambientales y culturales locales. Para la sierra, el control Inca posiblemente estuvo caracterizado de dos maneras, una comprendida dentro de la propuesta de Craig Morris, con la presencia de los grandes centros administrativos ubicados en áreas de marginalidad política, social y ecológica, desde los cuales se ejercía el dominio y control de las áreas adyacentes (Morris 1973: 138). Otro tipo de control Inca, tiene sustento etnohistórico, y fue el uso de mecanismos políticos en la participación de los grupos étnicos involucrados dentro del panorama sociopolítico anterior a la conquista Inca, estos tratos políticos son conocidos como "alianzas". Una vez que el estado Inca decidía conquistar una región, se enviaban emisarios de cada lado tanto de los Incas como de los locales, para mediar entre ambas partes y acordar el tipo de tratamiento en la conquista, si era violenta o si era pacífica, en este último eran considerados como aliados (Cieza 1553).

Tal es la situación política que le tocó vivir al entonces señorío Yauyo de la sierra de los valles del Rímac, Lurín y Cañete, quienes se aliaron a los Inca a cambio de ciertas concesiones. La etnohistoria da importancia a esta relación.

2.- Los trabajos de Farfán en Cantamarca, Huishco y Aynas manifiestan una presencia Inca significativa. De otro lado Cantamarca muestra una cantidad de qollqas de factura Inca ubicadas en su explanada distante del grueso de componentes del periodo anterior al dominio Inca. 
“....Los Yauyo pertenecian a una aguerrida población, llamada: Atun Yauyo: quienes se plegaron a las filas del Ejercito Incaico, prestando valiosos servicios; por lo que fueron considerados por los emperadores Cuzqueños como los jefes o gobernadores de las otras poblaciones que se mantuvieron, siempre rebeldes a la Dominación incaica...." (Huaman Poma de Ayala 1615 en Villar Cordova 1935: 75).

En otros documentos coloniales sobre litigios de tierras entre los señoríos de Canta, Collec y Quive del valle Chillón, se menciona muchas veces la presencia intrusiva de un grupo serrano procedente del Rímac. Estas mismas fuentes señalan que la conquista cuzqueña de la cuenca, fue llevada a cabo por medio de la colaboración del señorío Yauyo, el cual estaba formado por un conjunto de señoríos subalternos, entre los que se encontraba el señorío de Chaclla, que ocupaba la margen derecha del río Sta. Eulalia, por lo tanto, sus tierras limitaban por el lado norte con el señorío Canta, y siempre competían contra ellos por obtener el derecho a explotar los cocales de Quive ubicados en la Chaupiyunga o confluencia de los ríos Arahuay y Chillón. Fue en la época Inca y gracias a esa alianza, que los de Chaclla logran penetrar al Chillón usufructuando sus cocales, a la vez, que sirven de intermediarios para la administración Inca de ese producto (Rostworowski 1967: 20, 21). ¿Esto, nos estaría sugiriendo que los de Yauyo por intermedio de los de Chaclla, también controlaron administrativamente algunas secciones de la cuenca del Chillón?.

Se sabe que a la caída del Tahuantinsuyu, resurgieron nuevamente las encendidas rivalidades entre los de Chaclla y Canta, estos últimos reclamaron viejos derechos sobre las codiciosas tierras de Quive, motivando en la época colonial la producción de estas demandas y juicios entre las dos etnias involucradas.

\section{LA EVIDENCIA INCA EN Chaclla}

En el entonces señorío de Chaclla, después de la perturbación ocasionada por el dominio Inca, los espacios sociopolíticos de la región fueron modificados de acuerdo a los intereses de la política Inca. Arqueológicamente en la zona de Chaclla, aún no se han reportado estructuras arquitectónicas al estilo Inca ${ }^{3}$ tales como qollqas, kallancas, kanchas, etc., que nos podrían indicar poder e imposición de parte de ellos hacia las poblaciones locales (Pareja 1995). Esta evidencia negativa, nos estaría corroborando la hipótesis, que la política adoptada por los cuzqueños en el área de Chaclla, estuvo basada en una alianza como refieren los documentos, ¿Entonces, de que manera se habría manifestado la presencia Inca en los territorios de la margen derecha del río Sta. Eulalia?.

Según los estudios realizados por Jesica Pareja en la década de los años $90^{\circ}$ del siglo pasado, se han encontrado evidencia de cerámica Inca en dos sitios: Huambo (Figura 4) y Chuya (Pareja: 1995).

\section{Chuya}

3.- En el caso del sitio arqueológico Huambo, Jessica Pareja en base a documentación histórica y arqueológica señala una función religiosa que va desde el Horizonte Medio hasta la actualidad, el sitio también manifiesta arquitectura Inca como qollqas y una estructura de planta trapezoide, cuya presencia respondería más a la necesidad del estado Inca de asimilar las deidades locales como mecanismos de control social y político.

4.- De Huambo, podemos decir que este sitio posee planta ovoide cuyo diámetro en su eje menor es de $50 \mathrm{~m}$. paredes de hasta $2.50 \mathrm{~m}$. de altura, una sola entrada al noroeste de $1 \mathrm{~m}$. de ancho, al centro de la planta ovoide se ubica un pozo circular de $7 \mathrm{~m}$. de diámetro, el pozo presenta una cavidad cuadrada, en sus lados norte y sur se encuentran dos plataformas de $0.50 \mathrm{~m}$. de altura, se reporta material Inca en superficie como fragmentos de aríbalos, platos, asas, etc. 


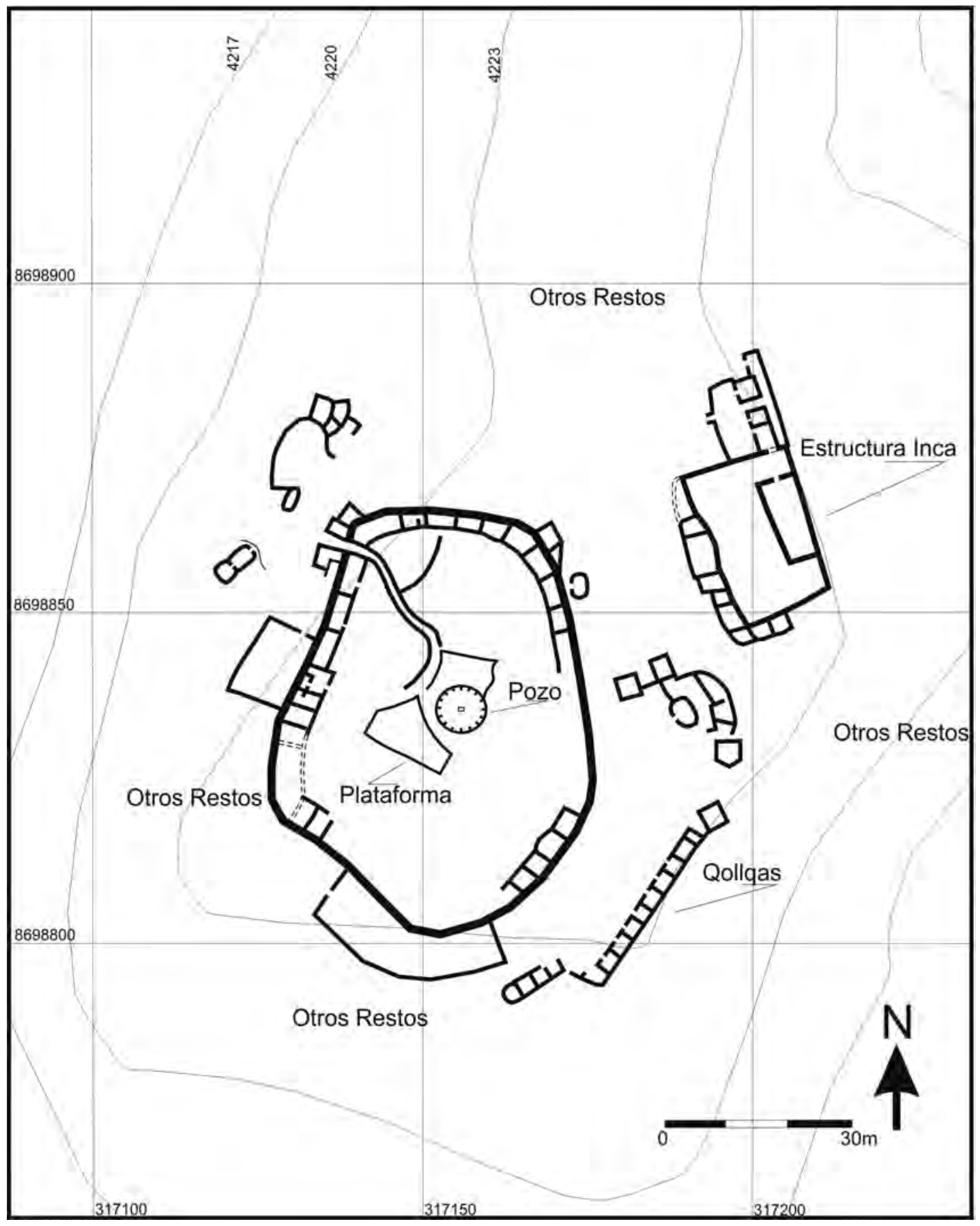

Figura 4: Sitio arqueológico Huambo. (Redibujado en base a Pareja 1995 e imágenes satelitales google earth 2003). 
El sitio arqueológico de Chuya se ubica en la margen derecha del río Sta. Eulalia en las pendientes de un pequeño promontorio rocoso, estratégicamente se haya emplazado en la confluencia de quebradas naturales que provienen por el norte del valle de Arahuay y por el sur del Sta. Eulalia, desprendiéndose luego una vía que va hasta la quebrada de Jicamarca en Huachipa (Figura 5). El sitio, tiene antecedentes culturales que van desde el Intermedio Temprano hasta la Inca, perteneciendo la mayoría de sus construcciones a las épocas más tardías (Pareja: 1995). Chuya se distingue del resto de asentamientos Chacllas, por que a pesar de guardar similitudes arquitectónicas locales, denota un planeamiento y organización mucho más elaborado que las demás construcciones del período Intermedio Tardío (Figura 6), esta conformado por varios conjuntos de unidades arquitectónicas de planta rectangular alargada que rodean espacios abiertos, tales construcciones por su tamaño, tienen un parecido a las kallancas incaicas, que en este caso poseen dos divisiones internas con una serie de compartimientos en la división posterior a manera de cajas, el cual es un rasgo difundido en la mayor parte de los sitios del Intermedio Tardío, y probablemente en Chuya sea una asimilación de ideas locales en la arquitectura Inca de la región.

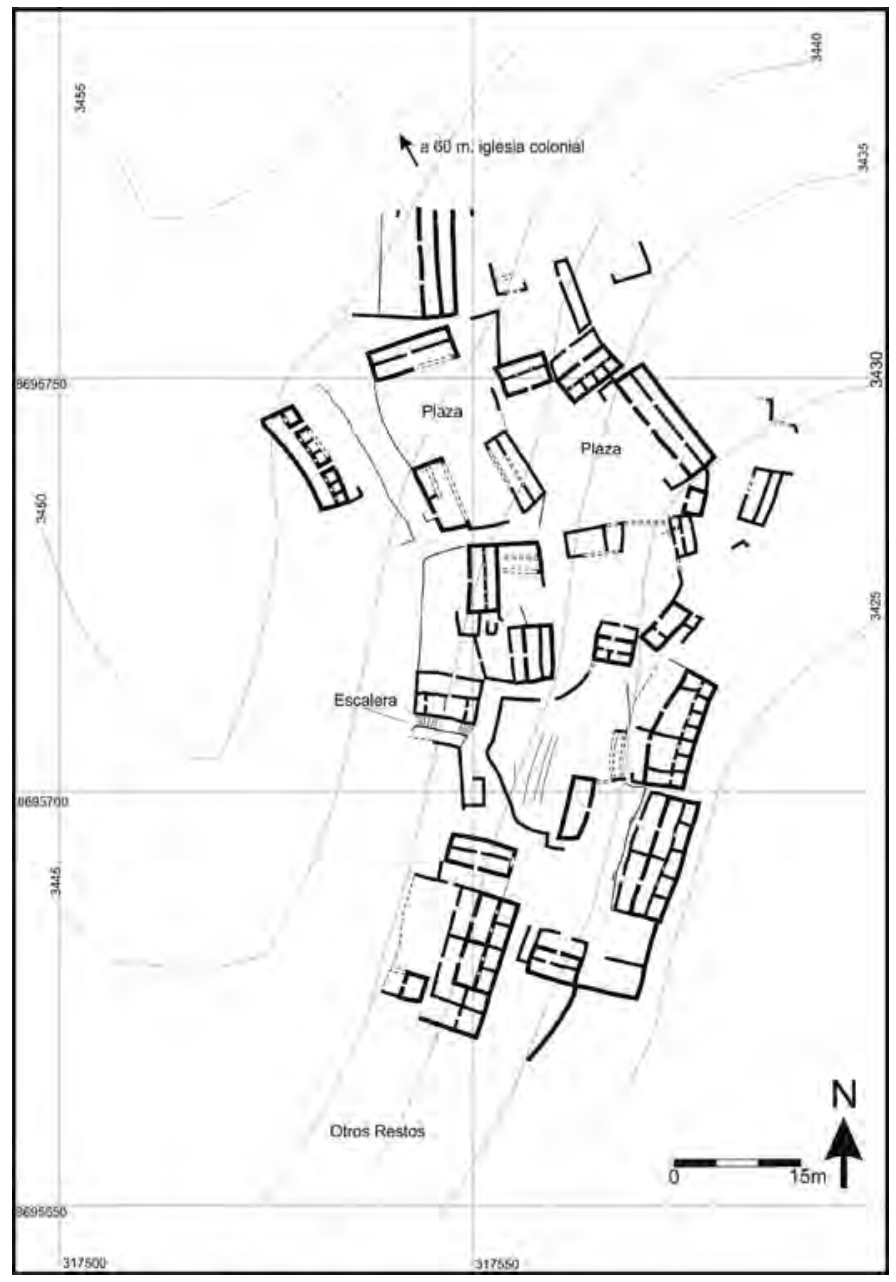

Figura 5: Principales componentes del sitio arqueológico Chuya (Redibujado en base a Pareja 1995). 


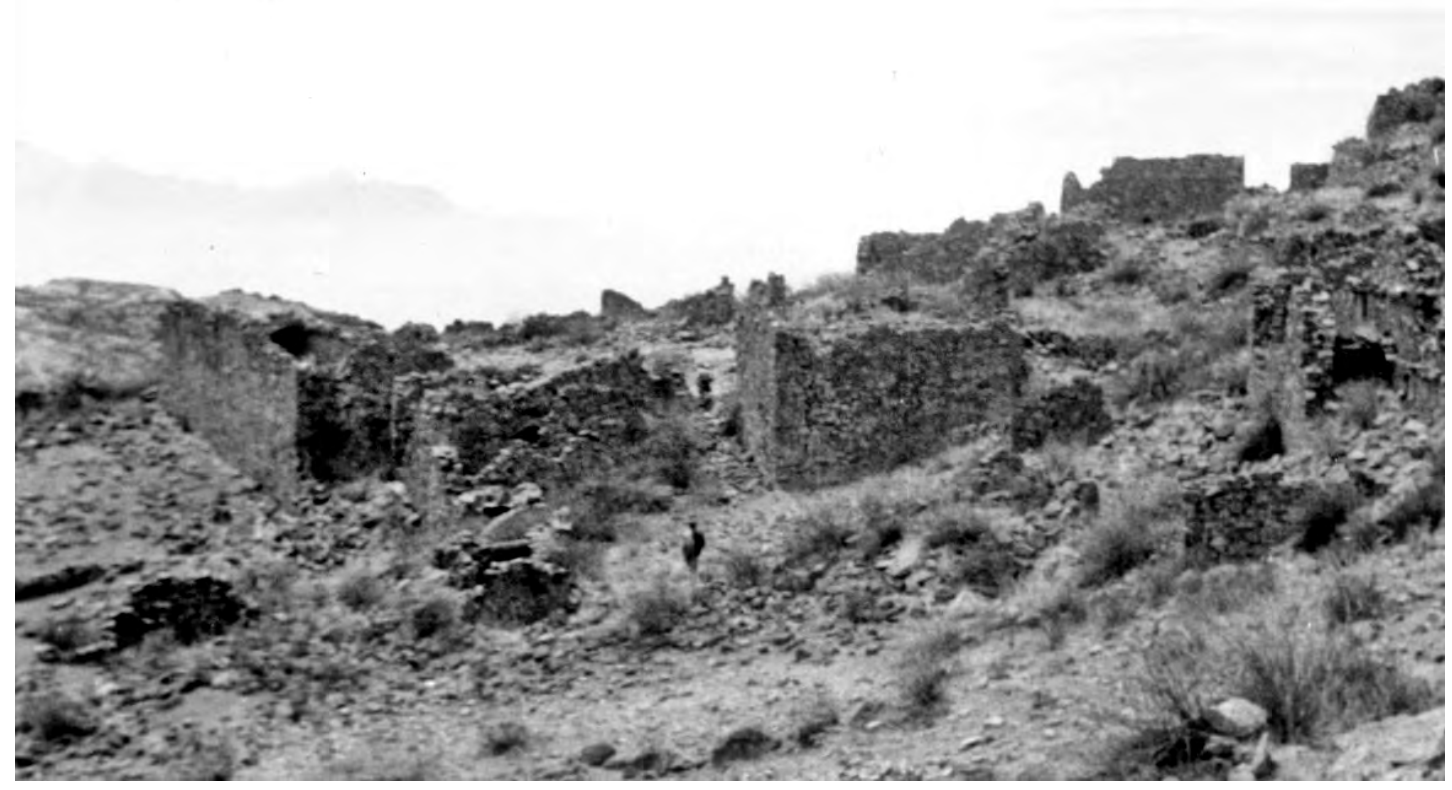

Figura 6: Estructuras de planta rectangular en Chuya

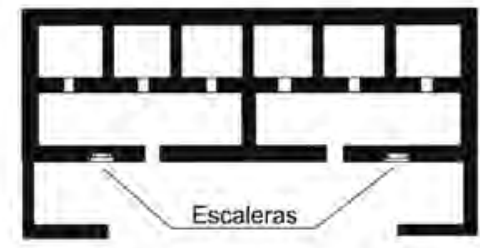

PLANTA

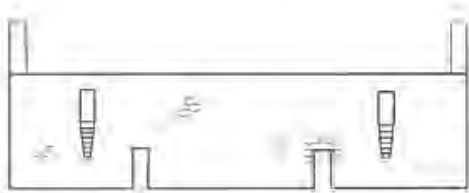

FRONTIS

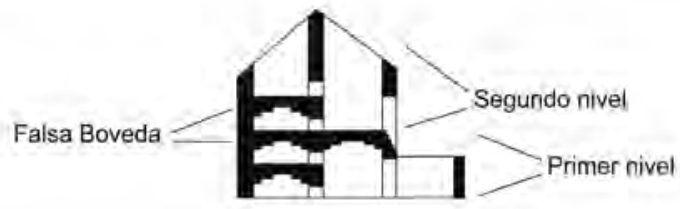

CORTE

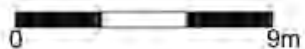

Figura 7: Dibujo esquematizado de una estructura arquitectónica del sitio arqueológico Chuya. 
Entre otros detalles constructivos el techo de los recintos de Chuya era de dos tipos: de falsa bóveda en los primeros niveles y de dos aguas en el nivel final cuando el recinto era grande (Pareja: 1995). Con respecto a este tema podemos decir que la estructura central del sitio arqueológico Inca de Aymará compuesto por un alineamiento de siete qollqas de planta rectangular presenta un techo de falsa bóveda en su primer nivel y muy posiblemente el segundo nivel lo era de dos aguas. (Figura 7 y 8). Observamos pues que existe la tendencia de construir empleando la técnica local de la falsa bóveda para estructuras típicas de planeamiento Inca.

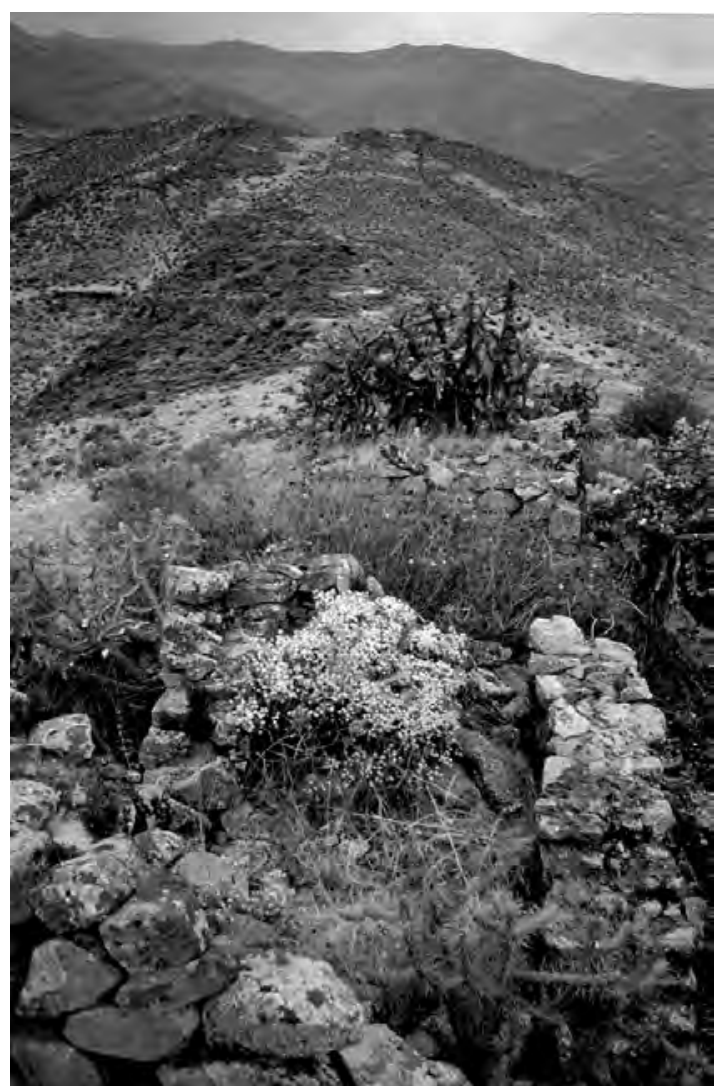

Figura 8: Las qollqas del sitio arqueológico Aymará

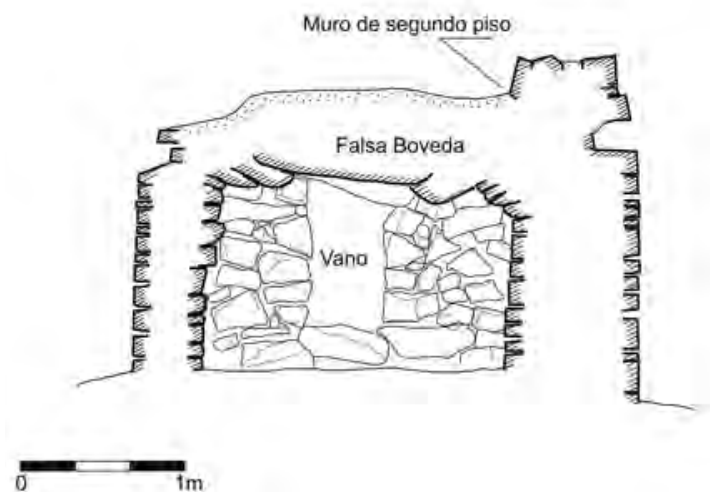

Figura 9: Corte y perfil este de la estructura central de Aymará.

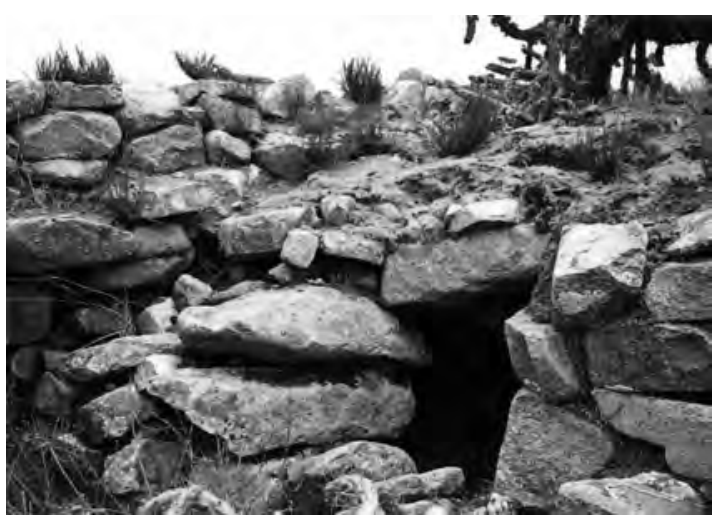

Figura 10: Vano de acceso y el techo de falas bóveda.

Asimismo nos indica que en Chuya se establecieron los cuzqueños para controlar y/o administrar a las poblaciones que vivían en la margen derecha del río Santa Eulalia; así, como a la ruta de intercambio entre la sierra y la costa central por medio de la Quebrada de Jicarmarca (Pareja 1995).

John Hyslop, cuando analiza la situación de los tampus en el Tahuantinsuyo, señala entre otros, la presencia de tampus de arquitectura local no Inca, pero construidos durante esta época en aquellos lugares donde la tradición local fue poderosa y se le permitió continuar desarrollándose (Hyslop 1992: 147). Probablemente tal situación ocurrió en Chaclla si a esto consideramos la alianza como trato, que pudo permitir el mantenimiento de las ideas constructivas Chacllas durante la dominación Inca. Por otro lado, según la documentación etnohistórica, Chuya estaba considerada como un lugar de mitmas traídos de la guaranga de Chaclla (Espinoza 1992: 155). Todos estos indicios nos hacen suponer que este sitio fue un importante establecimiento Inca en los territorios del señorío de Chaclla, y que a la 
llegada de los hispanos continúo funcionando como lugar de adoctrinamiento de la región ya que existe una iglesia colonial confundida como kallanca5.

Considerando las particulares características del sitio Chuya, era probable hallar otros sitios con arquitectura semejante en el Arahuay, que nos indicarían el control de parte de los de Chaclla de esta región durante la época Inca.

\section{El Camino Inca}

El camino Inca que comunica el valle del Arahuay (Figura 9) con el de Sta. Eulalia, tiene una trayectoria general norte-sur cubre una extensión aproximada de $32 \mathrm{~km}$. Este camino fue reconocido desde el poblado de Lachaqui en Arahuay hasta el sitio arqueológico de Chuya en Sta. Eulalia, tiene entre $4 \mathrm{~m}$. de ancho promedio, en la divisoria de aguas entre los valles de Arahuay y Sta. Eulalia su ancho máximo alcanza de los 7 a $9 \mathrm{~m}$.

El camino posee muros de contención, empedrados, se asocian apachetas como las de Sacayhuan$\mathrm{ca}$ a los $4300 \mathrm{~m}$. de altura. Muy cerca a la divisoria de aguas un ramal de camino se desprende y se dirige hacia Tunshuhuilca. Entre los sitios arqueológicos asociados se identificó el sitio arqueológico Hualpig a los $4300 \mathrm{~m}$. de altitud conformado por varias estructuras de planta rectangular y a pocos metros del camino, desde aquí se dirige hacia Chaclla y Chuya, no sin antes pasar por Kilkamachay, pueblo de neveros hasta mediados del siglo XX.

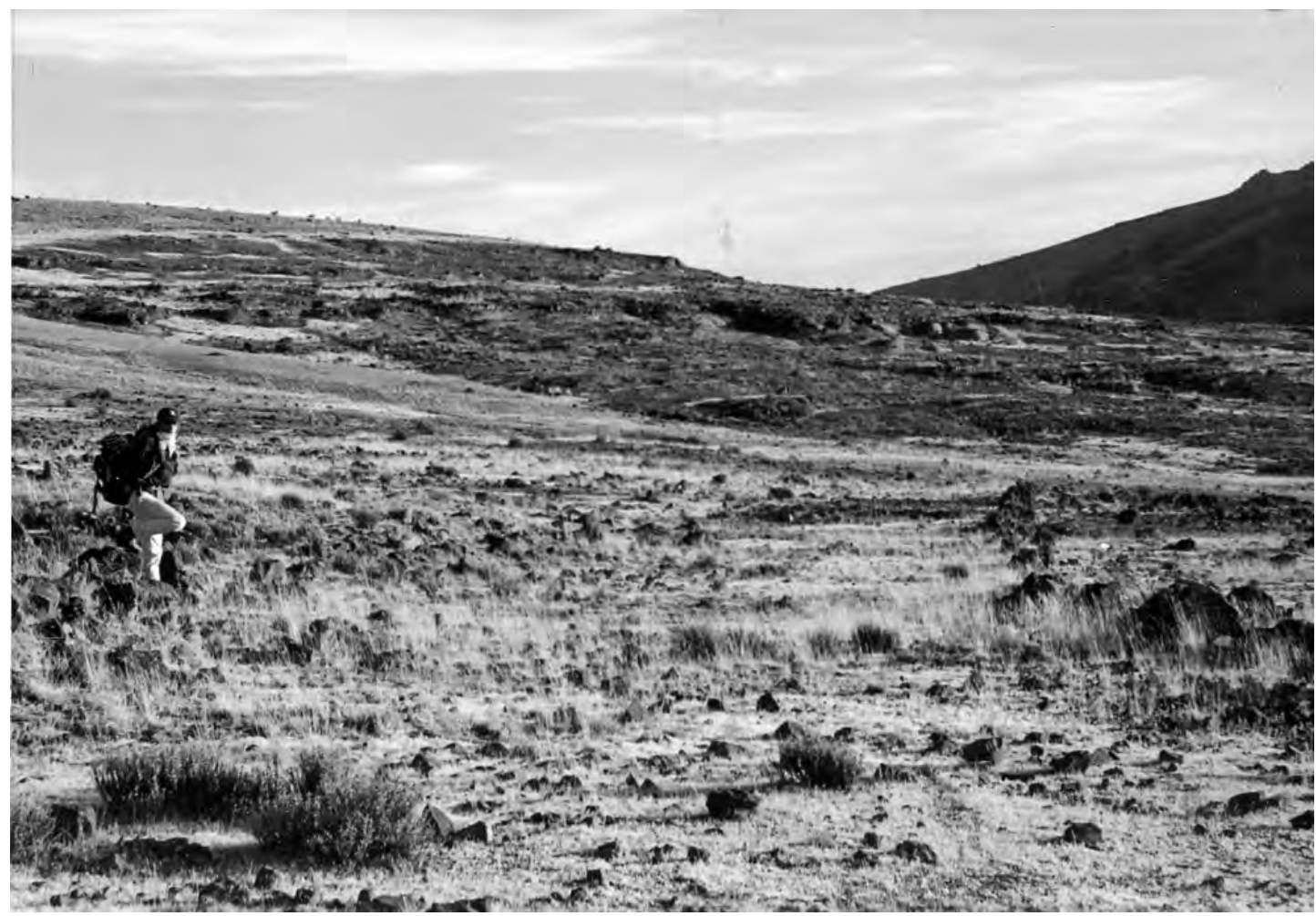

Figura 11: Sección de camino de $9 \mathrm{~m}$. de ancho.

5.- Existe mucha confusión entre la Kallanca y las primeras iglesias coloniales, puesto que la forma y diseño son muy semejantes, para mayor información recomendamos revisar Casaverde 2007, Casaverde y López 2010. 


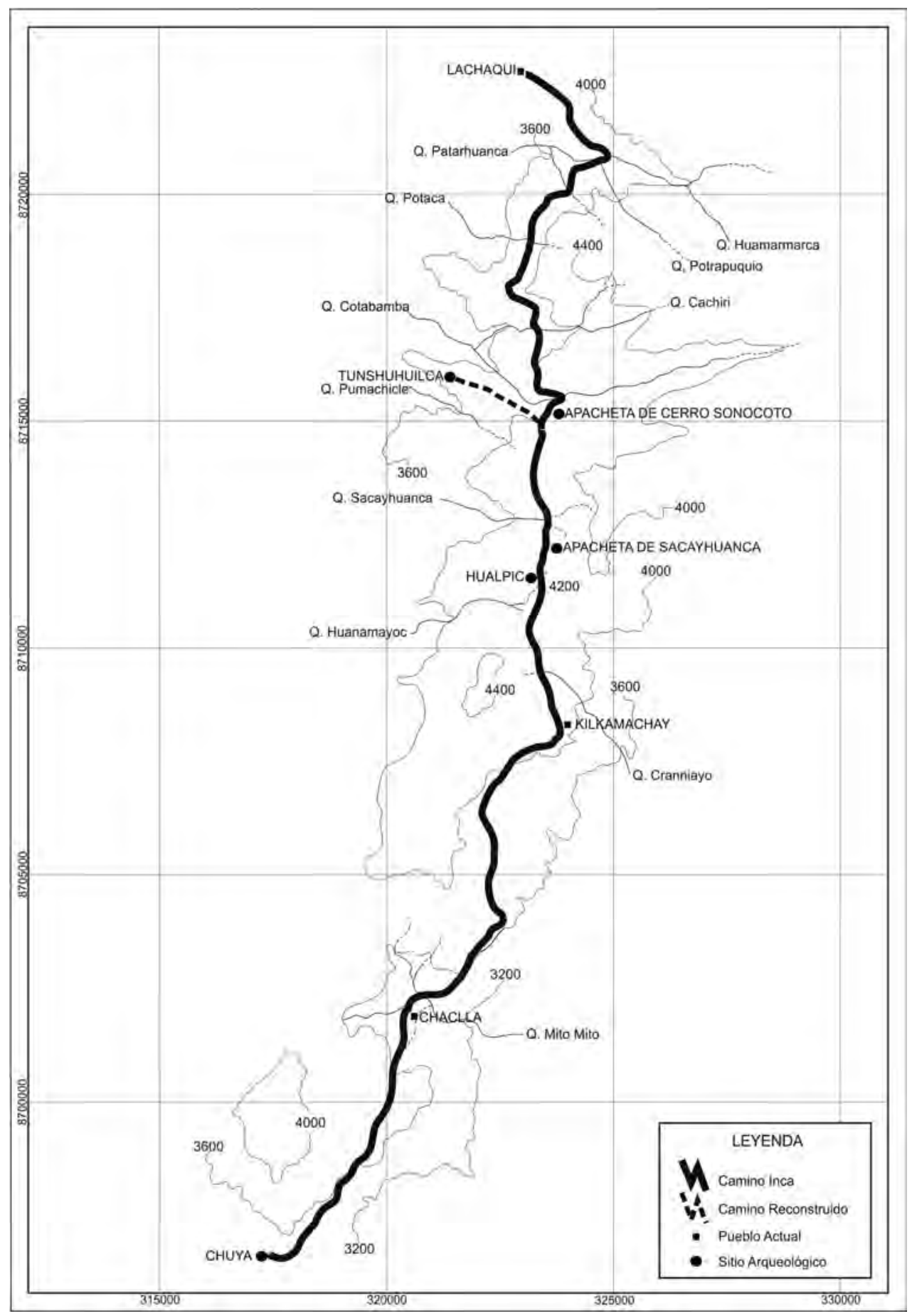

Figura 12: Ubicación del camino Chillón - Rímac. 


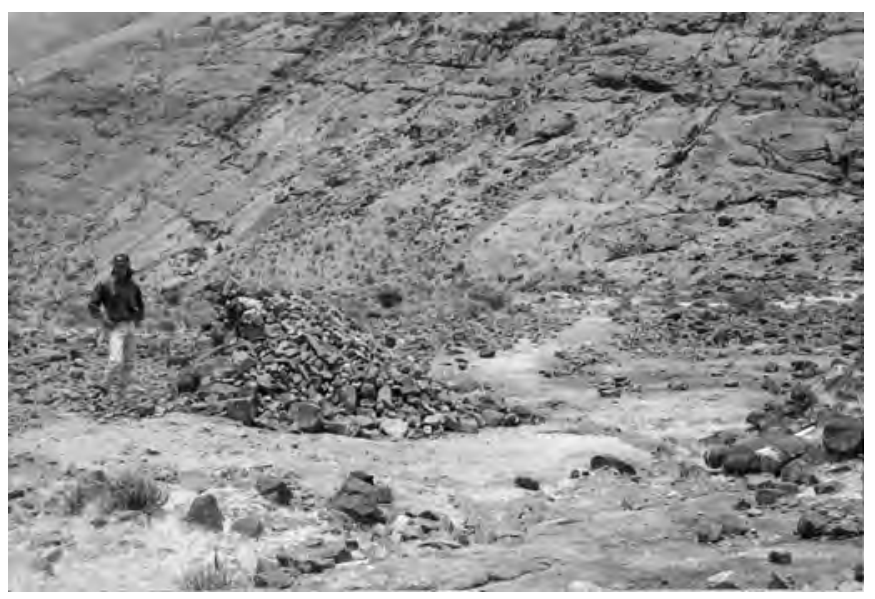

Figura 13: Apacheta de Sacayhuanca en la divisoria de aguas del Chillón y Rímac.

\section{Sitios INCAS EN EL VALLE}

\section{DE ARAHUAY}

\section{Tunshuhuilca}

Se encuentra ubicado en la margen izquierda del río Arahuay a 3,700 m. de altura, en la cumbre del cerro "Pueblo Viejo". La ocupación del período Intermedio Tardío, está compuesta por estructuras de planta rectangular, con varias divisiones internas, por otro lado, la presencia Inca está representada por un sector, cuya arquitectura es diferente al de los sitios de Cantamarca y Aynas del alto Chillón, donde la presencia Inca arqueológicamente ha sido notoria (Villar Córdova 1935, Farfán 1995).

El sector Inca (Figura10), se encuentra aislado a aproximadamente $100 \mathrm{~m}$. al noreste de las construcciones del período anterior, está compuesto por un agrupamiento de 3 estructuras de planta rectangular alargada con dos divisiones interiores siempre paralelas al lado mas largo, la división posterior tiene una mayor cantidad de pequeñas subdivisiones y varios niveles que la división anterior. Las tres estructuras encierran una plaza. Estas características arquitectónicas y de planeamiento, se

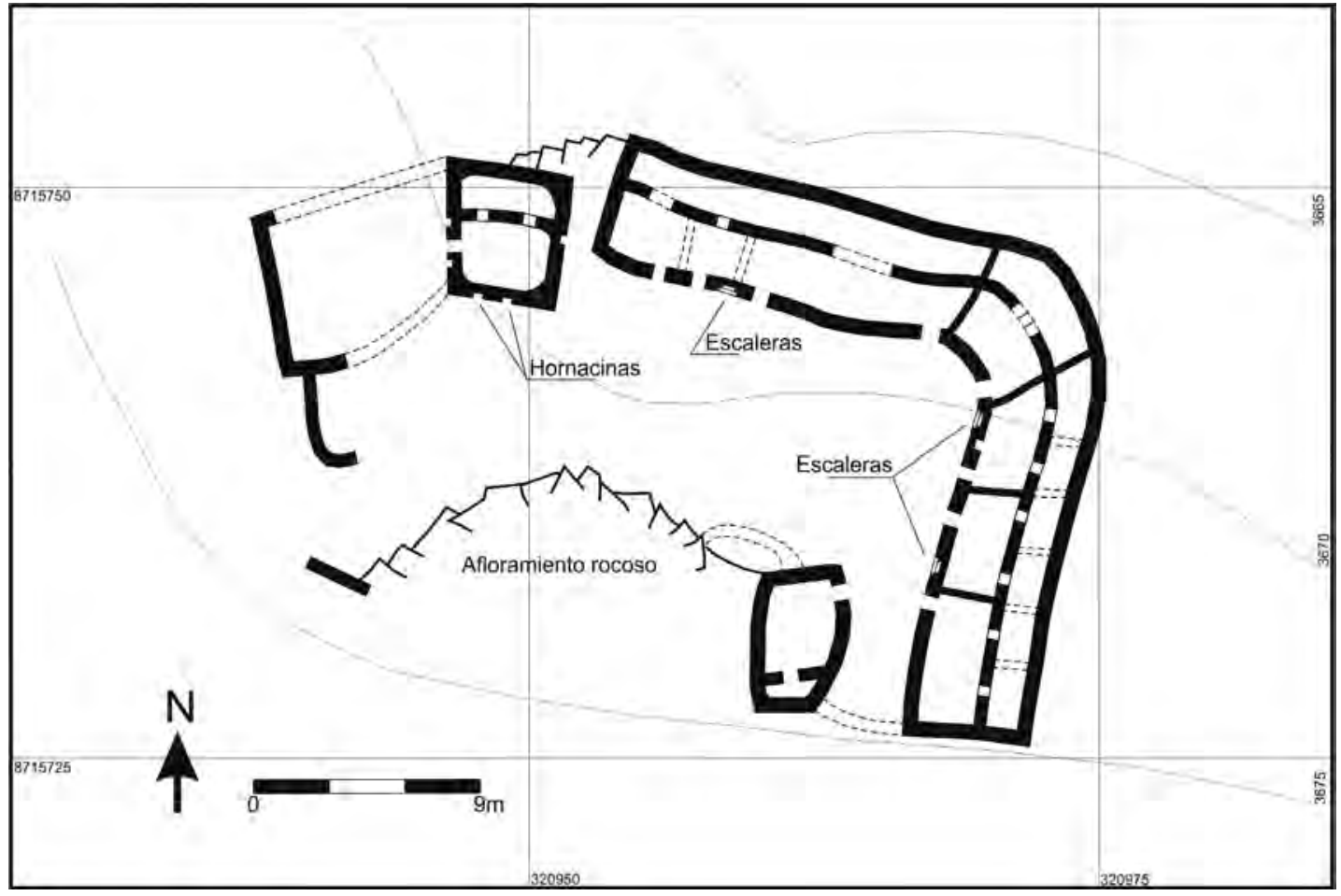

Figura 14: Sector Inca del sitio arqueológico Tunshuhuilca. 


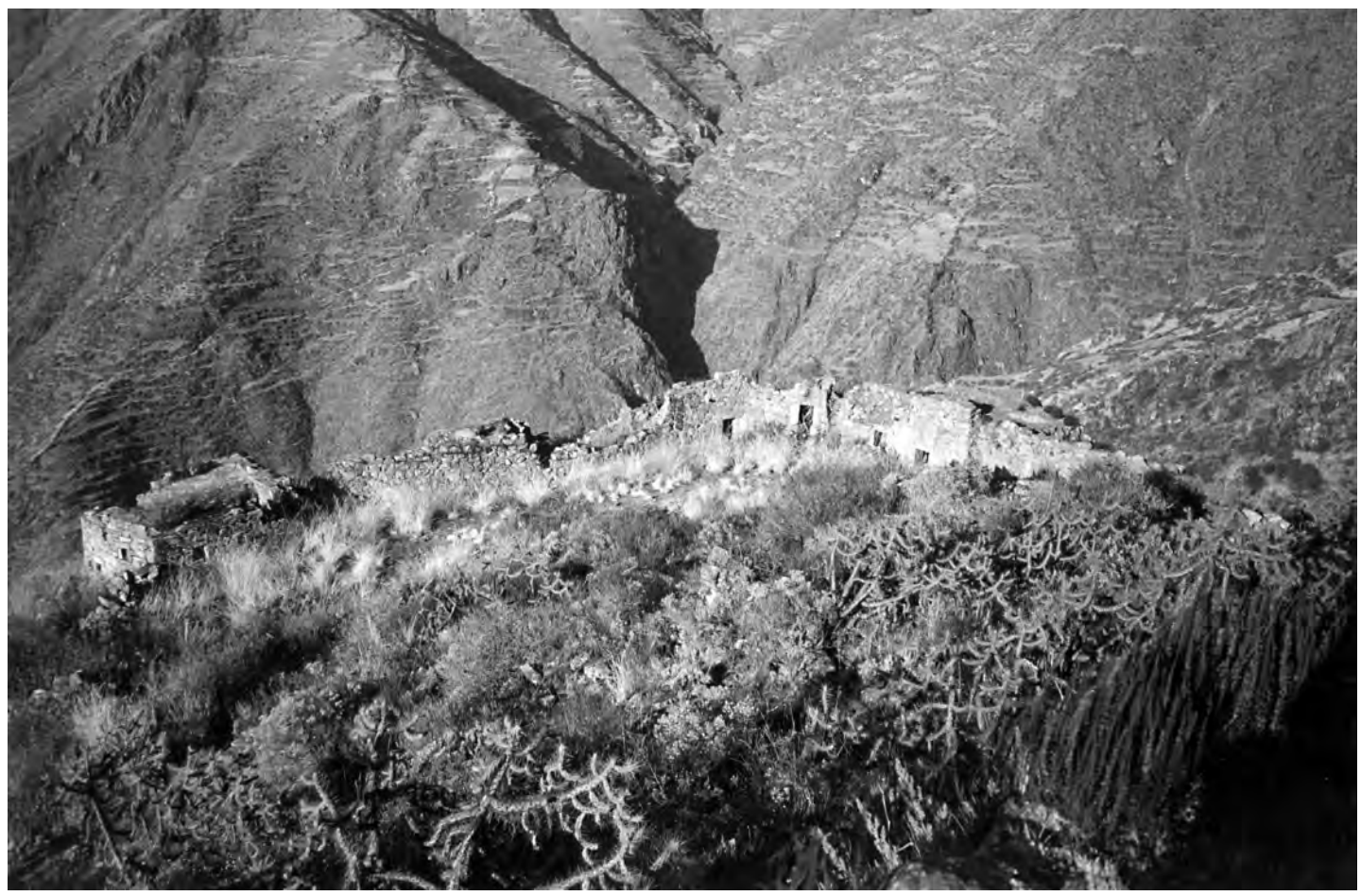

Figura 15: Sector Inca de Tunshuhuilca.

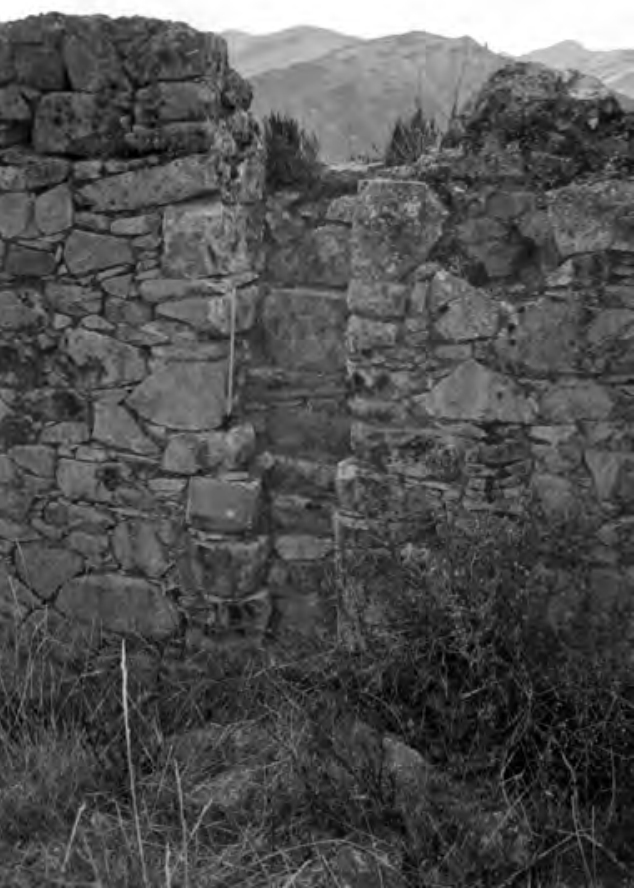

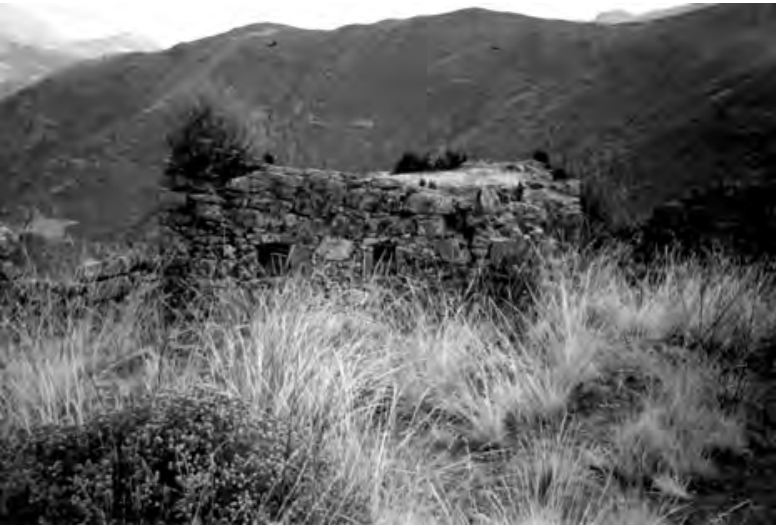

Figura 17: Estructura con hornacinas del sector Inca. 
asemejan al sitio Inca de Chuya tanto en su forma y contenido, además, en una de las construcciones se encontraron hornacinas trapezoidales de pequeño tamaño y fragmentos de cerámica Inca como aribalos de color negro fueron hallados en el interior de los recintos.

Según John Hyslop, la característica de aislamiento que presentan las construcciones Inca en los asentamientos locales, es propia de un tampu y puede reflejar algún tipo de tratamiento político Inca respecto de la población Local (Hyslop 1992: 147). Es posible que el sector Inca en Tunshuhuilca haya cumplido esta función.

\section{Caballo Blanco}

Se encuentra en las pendientes del cerro denominado Caballo Blanco que se interna en el valle de Arahuay a manera de espolón en la margen izquierda del valle de Arahuay y a $2000 \mathrm{~m}$. de altitud, a la altura del actual poblado de Licahuasi, el sitio está delimitado naturalmente por el valle de Arahuay al oeste y la quebrada de Chacalla al este.

Caballo Blanco, está protegido por 3 murallas consecutivas y una zanja, las cuales aparecen en el lado norte; el lado sur fue protegido por muros de contención que ahora están muy destruidos. Dillehay, Silva y Marcus habían notado el carácter de asentamiento Chaclla de Caballo Blanco (Marcus y Silva 1988: 48), ahora pensamos que este sitio tuvo alguna importancia en la época Inca.

La arquitectura que compone el asentamiento de Caballo Blanco (Figura 11), es a base de recintos rectangulares, que delimitan espacios abiertos, las construcciones tienen dos divisiones internas paralelas a los lados mas largos, la división inmediata al acceso del recinto, tiene pocas divisiones, en cambio la última que consta de dos niveles, las tiene en mayor cantidad. Estas características son semejantes al sitio Chuya, además la cerámica Inca es abundante en Caballo Blanco y en su mayoría lo conforman bordes de aribalos.

Es probable que Caballo Blanco haya sido un importante establecimiento Inca, su ubicación estratégica en las confluencias de dos vías naturales importantes, como el valle de Arahuay al oeste y la

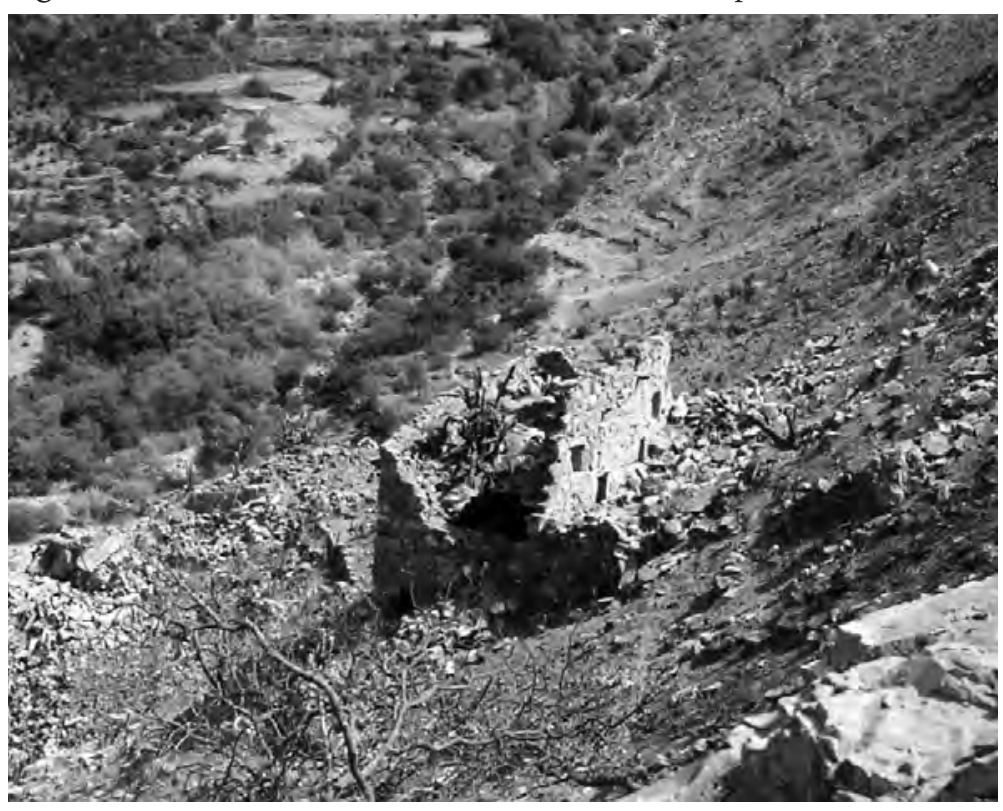

Figura 18: Estructura de Caballo Blanco. quebrada de Chacalla al este, le permitió controlar esta sección del valle. Además, Caballo Blanco se conecta por medio de un camino que va por la quebrada de Chacalla con la antigua reducción de Collata de la cuenca de Sta. Eulalia, y que en tiempos prehispánicos era parte del Señorío Chaclla. Por otro lado, la información etnohistórica sugiere que mitmas Chaclla originarios del pueblo de Collatamarca fueron enviados a Quive (Inf de Oficio-f. 117 en Rostworowski 1967: 20). Es posible, que las estructuras arquitectónicas de Caballo 


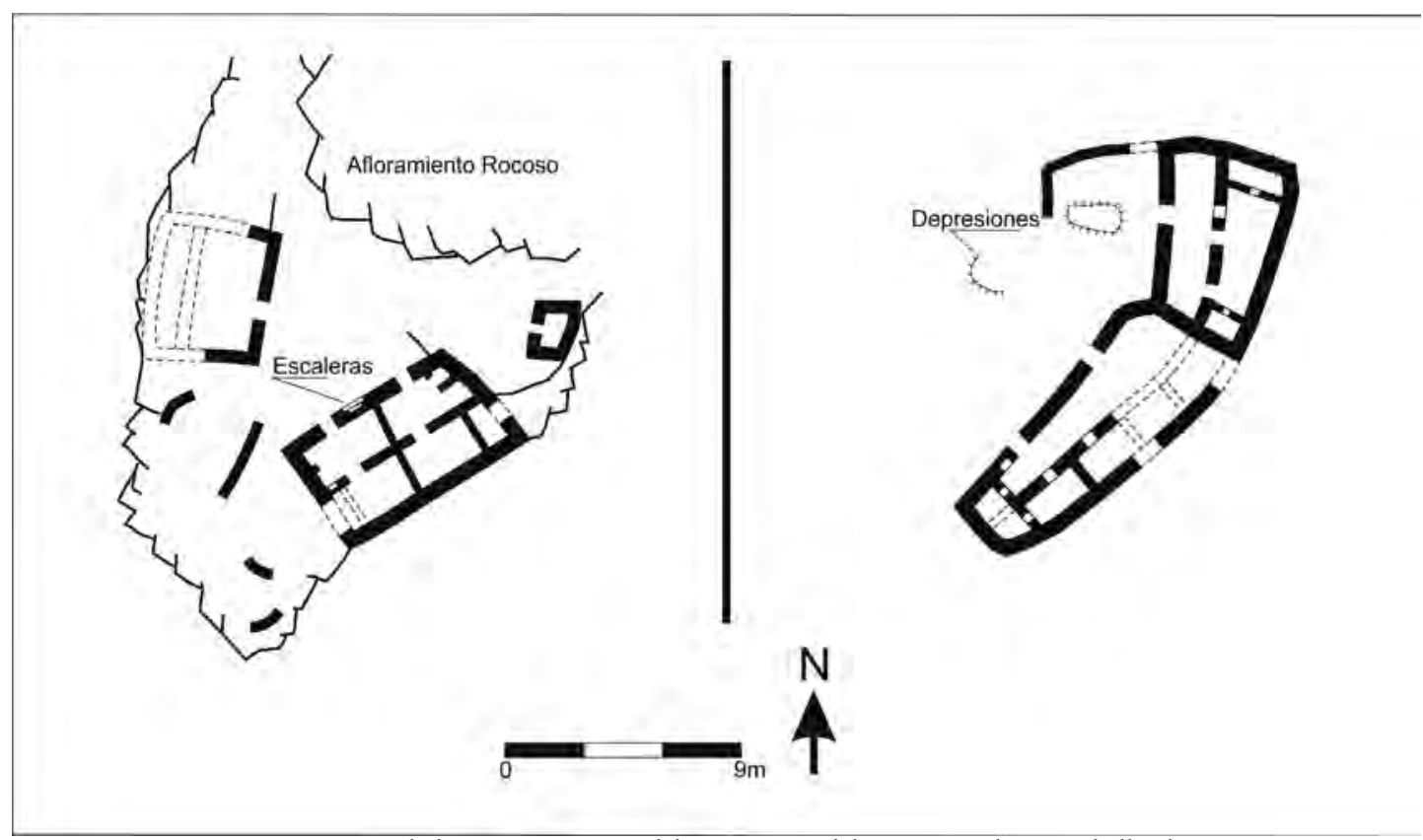

Figura 19: Dos unidades arquitectónicas del sector norte del sitio arqueológico Caballo Blanco.

Blanco, hayan tenido una función de almacenamiento y uso restringido, como lo manifiesta el sitio de Chuya.

\section{Discusión}

Hasta el momento, podemos afirmar de intensas relaciones entre los valles de Sta. Eulalia y Arahuay, evidenciados en las semejanzas arquitectónicas de los asentamientos y en la existencia de caminos de intercomunicación (Rostworowski 1967, Dillehay 1987: 423). Esta afirmación nos permite ampliar la discusión sobre la supuesta unidad del señorío Canta y sobre sus límites territoriales, ya que la etnohistoria arguye como parte del señorío, a las tierras del valle de Arahuay. Sin embargo a la luz de las investigaciones en el alto Chillón, es difícil aceptar la presencia de un solo señorío en esta región. La arquitectura de los distintos asentamientos de la cuenca alta no guarda homogeneidad alguna, repitiéndose también en el Arahuay. Probablemente el señorío Canta estuvo conformado por otras unidades socioculturares más pequeñas subordinadas a la capital Cantamarca, este modelo funciona cuando se constata la variedad de la cerámica como de la arquitectura ligada a las zonas de los valles aledaños, la margen derecha del Chillón alto vinculada más al Chancay y la margen Izquierda del Arahuay al del Sta. Eulalia, respondiendo esto a la manera en que las sociedades se hallaban integradas y vinculadas a áreas específicas de desarrollo, puesto que tenían ventajas al tener acceso y comunicación con las áreas colindantes a través de las quebradas laterales. Este proceso sociocultural fue encontrado por los Incas y es muy probable que se halle reflejado en la administración para ese periodo en la región.

Para la época Inca, y la consecuente expansión cuzqueña en las cuencas del Rímac y Chillón, trajo consigo la participación del señorío Chaclla. Las evidencias etnohistóricas como arqueológicas nos señalan que el control Inca de la cuenca del Chillón, principalmente del valle de Arahuay, estuvo dirigido por los de Chaclla. En Tunshuhuilca al menos existe un sector Inca cuyas características formales 
y de ubicación, son diferentes a lo establecido en el Intermedio Tardío del Arahuay, este sector y las construcciones que conforman el sitio de Caballo Blanco guardan mayores semejanzas con las construcciones del sitio arqueológico de Chuya del Sta. Eulalia. Es muy probable que, las relaciones políticas entre los de Chaclla e Inca, hayan conducido a la aplicación de ideas arquitectónicas de Chaclla, para ser luego llevadas al Chillón con ligeras variantes producto de las implicancias socioculturales de ese valle, este dato concuerda con la ausencia de estructuras arquitectónicas típicamente Inca en territorios Chaclla, que ya señalamos con anterioridad y con la presencia de tales estructuras en la margen izquierda de Arahuay cercanas a Chaclla. Tunshuhuilca por su parte se comunica por medio de un camino con el sitio de Chuya, distante en $32 \mathrm{Km} .{ }^{6}$ y Caballo Blanco hace lo mismo por medio de la quebrada de Chacalla que llega también hasta Chuya en unos $20 \mathrm{~km}$. aproximadamente.

Actualmente el sitio Inca de Aymará, ubicado en la parte alta de Arahuay al Norte de Tunshuhuilca, está considerado como uno de los límites demarcatorios entre las comunidades de Arahuay y Lachaqui. A partir de Aymará hacia la parte alta del Chillón, se encuentran estructuras con patrones constructivos netamente Inca, sucediendo lo contrario desde Tunshuhuilca hacia abajo, donde persistirían elementos arquitectónicos emparentados a Chuya.

Esto, nos mostraría un posible tratamiento político distinto en ambas partes, es decir con el aparato de control Chaclla en el Arahuay probablemente desde Caballo Blanco hasta Tunshuhuilca, y con una presencia Inca en la parte alta del valle del Chillón, de establecimientos Inca con los clásicos patrones arquitectónicos estatales, Aynas y Cantamarca muestran tales atributos (Farfán 1995: 35-48), y estaban bajo el control de este último. Mientras tanto, el control de Chaclla era más fuerte en el valle de Arahuay, e iba disminuyendo a medida que este iba subiendo, hasta toparse con los aguerridos Canta. Posiblemente tal sea el caso de la existencia del único sector Inca en Tunshuhuilca.

El registro arqueológico nos parece indicar que los de Chaclla durante la época Inca llegaron hasta Tunshuhuilca, por diversos medios políticos como consecuencia de la alianza con los Inca, llevando consigo una presencia por medio de la arquitectura semejante al de Chuya. La etnohistoria manifiesta que a la caída del Tahuantinsuyu las instalaciones Inca fueron abandonadas, posiblemente Caballo Blanco y el sector Inca de Tunshuhuilca corrieron tal suerte al no contar con la garantía que le prestaban los cuzqueños.

Ahora sabemos que las relaciones sostenidas en la cuenca alta del Chillón, giraban en torno a los intereses políticos y económicos de cada una de las sociedades que participaron en la región como los Inca, Chaclla y Canta.

\section{A MODO DE CONCLUSIÓN}

Las evidencias arqueológicas como etnohistóricas entre los valles del Arahuay y de Sta. Eulalia nos permite proponer la hipótesis de un control durante el periodo Inca por parte de sus aliados Chaclla hacia el valle del Arahuay, ya que ambas localidades comparten rasgos arquitectónicos semejantes en el diseño de las construcciones para dicho periodo.

La alianza entre los Inca y Chaclla se habría manifestado culturalmente en la casi total ausencia de estructuras arquitectónicas típicas Inca, de otro lado, las pocas evidencias de arquitectura Inca que se presenta en Chaclla, está relacionada a la función religiosa de Huambo, cuya presencia obedece más a la necesidad de asimilar las deidades locales como mecanismos de control social y político por parte de los Inca.

6.- En el camino Inca de Cajatambo a Pumpu, se identificó como distancia promedio de $32 \mathrm{Km}$. entre cada uno de los establecimientos Inca que se ubicaron en el camino. 
Finalmente una red de caminos iba desde el Arahuay hacia Santa Eulalia, el cual habría conectado estos dos espacios desde tiempos prehispánicos.

\section{Agradecimientos:}

Quiero agradecer a los compañeros de la UNMSM quienes me acompañaron indistintamente para la realización de esta investigación, en especial a Jessica Pareja, Edwín Rivera, Manuel Guerrero, Mary Espinoza, sin el esfuerzo compartido y sin su apoyo desinteresado como también es recorrer los Andes con un mapa en mano y la mochila de grandes proporciones sobre los hombros, no se hubiera concretizado las metas propuestas de esta investigación, sobre todo en un periodo de convulsión socio-política que vivía nuestro país allá por los años 90.

\section{BiBLIOGRAFÍA}

CASANA, Teodoro.

1976 Restos Arqueológicos de la Provincia de Canta y de la Provincia de Huaral. Imprenta del Colegio Militar Leoncio Prado. 238 p. Lima.

CASAVERDE RÍOS, Guido.

1995 Redes viales Inca en la Cuenca Alta del Río Chillón. Manuscrito inédito presentado para el pregrado UNMSM.

2007 Periodo de Transición. Colonial Vs Inca: El Caso de la Sierra de Lima. En Revista Kullpi Investigaciones Culturales en la Provincia de Huaral y el Norte Chico, Año 3 Número 3. p. 317 - 326. Lima

CASAVERDE RÍOS, Guido y Segisfredo LÓPEZ VARGAS

2010 Principios Metodológicos para la Identificación y Registro Arqueológico de los Caminos Inka. Inka Llagta, Revista de Investigaciones Arqueológicas e Etnohistóricas Inka. Año 1 Vol. 1. p. 79-101. Lima.

CIEZA DE LEON, Pedro de.

1962 [1553]La Crónica del Perú (1ª. Parte). Espasa-Calpe, Madrid 1962.

1967 [1553]El Señorío de los Incas (2ª Parte) de La Crónica del Perú. Instituto de Estudios Peruanos, Lima.

\section{DILLEHAY, Tom D}

1987 Estrategias Políticas y Económicas de las Etnias Locales del Valle del Chillón Durante el Periodo Prehispánico. Revista Andina. Publicación del Centro de Estudios Rurales Andinos Bartolomé de las Casas. N² 2, Año 5, p. 407-456. Cuzco.

1977 Tahuantinsuyo Integración Of The Chillón Valley, Perú Case of The Inca Geo-Political Mastery. Journal of Field Archaelogy. Vol. 4, N. 4, p. 397-405. Boston

ESPINOZA SORIANO, Waldemar.

1992 Huarochirí y El Estado Inca. Huarochirí, Ocho Mil Años de Historia. Municipalidad de Sta. Eulalia de Acopaya. Tomo I, Lima-Huarochirí p. 117-195. 
FARFÁN, Carlos

1991 Intermedio Tardío en los Andes Centrales Sobre la Base de Investigaciones en la Cuenca Alta del Chillón: Cantamarca, Huisco. Seminario de Turismo y Arqueología de la Asociación Peruana de Arqueología. Serie: Seminarios APA. Lima.

1992 Los Asentamientos Prehispánicos de Altura y su Relación con el Espacio Geográfico en la Cuenca Alta del Chillón. Boletín de la Sociedad geográfica de Lima. Segundo Congreso Internacional de Geografía de Las Américas. Tomo II. Volumen N: 105 Texto de ponencias. Lima

1995 Asentamientos Prehispánicos de la Cuenca Alta del Chillón. Gaceta Arqueológica Andina, №24 p. 31 - 61 Instituto Andino de Estudios Arqueológicos, Lima.

HYSLOP, John

1992 QHAPAQÑAN. El sistema vial Inkaiko. Trad. de Eduardo Arias. Instituto Andino de Estudios Arqueológicos (INDEA). Lima, pp. 137-170.

MARCUS, J. y SILVA, J.

1988 The Chillón Valley Coca Lands: Archaeological Background And Ecological Contex. Studies in Latín American Etnohistory and Archaeology, Memoirs of the Museum of Antropology. University of Michigan, Number 21. Vol. IV. P. 1-52.

MORRIS, Craig

1973 Establecimientos estatales en el Tawantinsuyu: una estrategia de urbanismo obligado. Revista del Museo Nacional. Tomo XXXIX; pp.: 127-141. Lima.

ROSTWOROWSKI DE SIEZ CANSECO, María.

1967 Etnohistoria de un Valle Costeño Durante el Tahuantinsuyo. Revista del Museo Nacional. Tomo XXXV. P. 7-61. Lima

1973 Plantaciones Prehispánicas de Coca en la Vertiente del Pacífico. Revista del Museo nacional. Tomo XXXIX, p. 193-224. Lima.

1977 Etnia y Sociedad: Costa Peruana Prehispánica. Instituto de Estudios Peruanos. Lima

1978 Señorios Indígenas de Lima y Canta. Instituto de Estudios Peruanos, Lima.

SILVA, Jorge

1992 Patrones de Asentamiento en el Valle del Chillón. Estudios de Arqueología Peruana. Fonciencias, p. 393-403. Lima

PAREJA CARRIÓN, Jessica.

1995 Patrones de Asentamiento en la Cuenca del Ríos Santa Eulalia. Manuscrito inédito presentado para el pregrado UNMSM.

VILLAR CORDOVA, Pedro Eduardo

1935 Las Culturas Prehispánicas del departamento de Lima. Ediciones Atusparia, Lima. 
